\title{
UNDERLYING REASONS BEHIND THE SUSTENANCE OF RAGGING IN SRI LANKAN \\ UNIVERSITIES: Findings from a state university in Colombo, Sri Lanka.
}

\author{
HETTIARACHCHI. A. A \\ University of Moratuwa, Katubedda, Sri Lanka \\ anishkah@uom.lk
}

\begin{abstract}
Ragging is a deep-seated long-lasting social practice found in the state university system of Sri Lanka. Considering the negative, damaging impacts on physical, psychological, social, cognitive and behavioural aspects of undergraduates, it has been identified as a punishable offence under the Prohibition of Ragging and other forms of violence in educational institutions Act, No. 20 of 1998. Despite the array of harmful effects, ragging has evolved during the past five decades and sustained thus far amidst severe punishments imposed. The objective of the current study was to identify the underlying deep-rooted reasons behind sustenance of ragging in state universities with reference to a selected university (UOX) in Colombo, Sri Lanka. In-depth interviews were conducted with a heterogeneous sample $(n=20)$ of volunteers. The study exposed an interconnected feeding system comprised of a minority of significant personnel among freshers, seniors, student unions, staff, administration, industry and political parties who play a decisive role in justifying the need and thereby support the sustenance of ragging. These findings may enable university authorities to find creative and innovative solutions to combat this menace to create a conducive academic environment for the future student community of State Universities in Sri Lanka.
\end{abstract}

Keywords: ragging, state universities, conducive academic environment

\section{Introduction.}

Ragging has been reported to have caused severe impacts to undergraduates ranging from psychological imbalances/disorders (anxiety, stress, depression, phobia, trauma, PTSD, ignominy, alienation, isolation, demoralization, detrimental impacts on personality, repressed unpleasant memories), physiological damage (physical injuries, rhabdomyolysis, hemolysis, heart attacks, deaths) to long term disabilities and even suicide (Bandara 2002, Athukorala 2018, Jayarathne 2019). Several suicides and brutal murders are among the ragging related deaths reported in the universities while some are unresolved yet but suspected to be connected to ragging (Daily Mirror, 2016). Ragging related abusive conduct further has unfortunately resulted in many students dropping out of university education while many others eligible for University education refraining from getting enrolled in state universities.

Considering its damaging nature, ragging is officially prohibited in universities/educational institutions and is a punishable offence under the Prohibition of Ragging and other forms of violence in educational institutions Act, No. 20 of 1998 (Jayasinghe,2017). No matter how much ragging is harmful, it has been sustained to date unabated at academic institutes despite severe punishments stipulated by the act having being imposed (Jayawardhana and Gamage 2017 and Bandara, 2002, p.1). According to the Minister of Higher Education ( Daily Mirror, 2018), even if the ragging act of 98 provides for the students found guilty of ragging to be sentenced to ten years rigorous imprisonment, it has not been heard of students meted out any prison term for the past 20 years despite ragging incidents reported and students being arrested occasionally.

On the other end, Dewasisri cited in (Jayasinghe, 2017) clarifies that, University authorities don't have a proper mature strategy to counter ragging. He highlights the necessity for a zero-tolerance ragging policy and proposes that ragging should be isolated and dealt with, but without imposing restrictions on other student activities which meaningfully nourish their experience as an undergraduate of a particular university.

The current situation of ragging in Universities is disgraceful. As highlighted by Wajahat (2013) a noticeable increase has been observed in ragging all over the world, especially in Southern part of Asia 
including India, Bangladesh, Pakistan, and Sri Lanka.

1.1 OBJECTIVES OF THE STUDY

There are many reasons behind the sustenance and continuation of ragging (Rajasingham, 2017). In view of this, the proposed investigation will look in to the reasons behind the sustenance of ragging amidst all the combatting mechanisms implemented so far. The study will attempt to seek

- The background, nature and prevalence of ragging

- Main agendas and expected outcomes of ragging

- Types of harassments caused due to ragging

- Underlying reasons for ragging to persist.

\section{Review of Literature}

Ragging was never heard of in the history of the pioneering educational institutions like 'pirivenas' in the Sri Lankan context. Following the tradition of British universities, 'ragging' entered our vocabulary subsequent to the introduction of university education in Sri Lanka (Bandara, 2002, p. 11). Taking inspirations from the universities, ragging expanded to vocational training institutes, central colleges, government schools, teacher training colleges, technical colleges, national colleges of education, forces, police services and many other places causing negative impacts to the student community as a whole (Bandara, 2002, p. 11).

\subsection{DEFINITIONS FOR RAGGING}

As defined by Rajasingham (2017), ragging is a deep-seated social practice. Elaborating this sociological dimension, Gamage (2017) identifies this to be linked with the general stratification of society along various hierarchies and power imbalances between those who wield power and those who are the subjects of such hierarchies. Highlighting another facet, Gamage (2007) further identifies ragging as a phenomenon that has arisen as a result of the sexual and romantic deprivations of male students who are away from their usual places of residences or birthplaces. Daily Mirror (2016) highlights that the temptation for ragging is nothing other than a psychopathic condition. Involvement of sexual abuse in many ragging cases clearly points to the sadistic side of the ragger's mentality. As explained by psychologists and psychiatrists' students with psychological imbalances; mania, sadism, body dysmorphic, loathing, Anti-social personality, abused childhood, separation anxiety, personality disorder ...etc are the ragging perpetrators (Athukorala, 2018 and Jayarathne, 2019). The ones who are underserved, underprivileged, discriminated, cornered during schooling/from society use ragging as an avenue to transfer their pressure to a weaker target (as a defence mechanism) while attempting to gain authority and recognition (Athukorala, 2018). Bringing another dimension in to light, Gamage ( 2020) explains ragging as a political enterprise, an instrument of political indoctrination which is used by a certain political party to gain recruits for demonstrations, picketing, etc and to raise funds for their political activities.

\subsection{FORMS AND NATURE OF RAGGING}

Ragging can be seen in one or a combination of modes mentioned below in the Sri Lankan universities.

- Verbal harassment: Verbal aggression, shouting, scolding, bullying, scolding over the phone, obscenity, filth

- Physical harassment: Forced to engage in student group activities, events, physical exercises, forced exposure to severe weather

- Psychological harassment: stalking, following, humiliating, staring at, cyber harassment/bullying/blackmailing 
- Sexual harassment: Unwelcome sexual comments or jokes, touching in a sexual manner without consent, forced to write or say obscene words, forced to expose private / sexual parts of the body, watch pornographic material, perform sexual acts that are degrading, forced sexual acts without consent

\subsection{EXPECTATIONS OF THE PERPETRATORS BY THE ACTS OF RAGGING}

Raggers represent a minority compared to the overall student population in any university. Literature establishes following as key expectations of ragging ( Athukorala 2018 and Jayarathne 2019).

- Mental satisfaction

- Releasing stress / compulsions

- As a means of catharises; vent ones suppressed impulses, frustrations, unresolved childhood conflicts

- Dominance; sense of superiority, seeking authoritative power/leadership/recognition

- Sublimation- Ragging as a defence mechanism; coping of internal conflicts/impulses in a socially acceptable form

- Gratification of sadistic tendencies: opportunity to satiate one's sadistic demands

- Projection of sexual desires/ sexual pleasure

- Fulfilling hidden abnormal sexual desires

- students who were ragged by their seniors transferring the pressure to their juniors; "I give back what I got before"

- Getting rid of peer pressure

- Fulfilling political agendas

Ragging perpetrators (seniors) under the guise of 'orienting' first year students (freshers) and making them 'conditioned' to the new surroundings, torment freshers ranging from undisciplined haughty speech to violent physical activities which can be equivalent to torture (Devapriya cited in Bandara, 2002). On the other hand, the pro-ragging staff members and students are hesitant to reveal the reality behind ragging or accept the fact that ragging is persisting to safeguard their popularity. However, it is vital for this minority to understand that they will be un-popularized not because they reveal the truth behind ragging but because they safeguard the raggers (Devapriya cited in Bandara, 2002).

As a matter of fact, ragging has evolved during a period of more than 50 years and exists in the university system up to date regardless of all the punishments and disciplinary actions imposed. The sustenance of ragging this long may be supposedly due to certain deep-rooted core values transferred from generations to generations by a certain group of people of a certain caliber. Further, there are concerns on the ineffectiveness of existing methods of complaining about ragging and violence to the university authorities and subsequent actions taken on ragging within the university system. As responsible academics and citizens of the country, it is vital to find solutions/ mechanisms to minimize and eliminate ragging /violence to make universities safe, healthy and conducive for future generations. Further, it is vital to identify and extract the useful, beneficial co-values of ragging (if any) and develop innovative and creative mechanism in achieving such objectives in a totally harmless yet meaningful and effective manner. In line with this, the current investigation probes in to the underlying reasons behind the sustenance of ragging in Sri Lankan universities, selecting a state University in Colombo, Sri Lanka as a case study.

\section{Research design}

\subsection{ACKNOWLEDGEMENT}

The current investigation was executed as a follow up inquiry catalysed by the study on "Ragging and Gender Based Violence (SGBV) in Sri Lankan University system \& implementing / proposing 
interventions and mechanisms for combating ragging and sexual and gender-based violence in the Sri Lankan university system", embarked upon by the UGC from July 2018 to January 2019 (funded by UNICEF). Aforementioned study included a paper and pencil survey, an online survey (in three languages) as well as in-depth interviews and focus group discussions for both staff and students. This was conducted in 8 Universities around the country and the university considered in the current investigation (hereinafter mentioned as UOX) was within the sample selected by UGC as detailed below and coordinated by a research team appointed by the vice chancellor. The details are as below.

Students' Survey - n = 1029 (Male 60\%, female 40\%)

Staff survey $-\mathrm{n}=181$ (Male $40 \%$, female $60 \%$ )

In-depth interviews (both staff and students representing all faculties, departments, divisions) $-\mathrm{n}=12$

Focused group discussions $-\mathrm{n}=8$ groups

The responses of the above study indicate the prevalence of ragging and harassments at UOX, though not in a significant level. For instance, verbal aggression (23\%), name calling (27\%) and other verbal acts (50\%) have been identified by the subjects as prevailing. It was seen that there is a psychological impact over undergraduates via spreading rumours (10\%) and pressure coming from others controlling what students do (9\%). The responses, though insignificant in numbers, indicate the prevalence of unpleasant experiences at some of the buildings/locations of UOX; canteens (27\% total), university grounds (14\% total), labs/lecture halls (11\%) and hostels (7\%). Though (99\%) of the subjects deny their involvement in ragging, $26.76 \%$ of subjects have agreed that they have been ragged during their stay as an undergraduate which clearly signifies the prevalence of ragging at UOX. The overall responses with reference to acts of violence based on sex/gender at UOX was insignificant. However, treating differently due to gender (10\%), staring at them making them feel uncomfortable (10\%), offensive remarks on one's physical appearance (7\%), repeatedly told sexual jokes/stories (5\%) and whistling/calling/hooting in sexual way (5\%) were identified by some respondents though they do not represent significant numbers.

The study conducted by UGC provided opportunity to have an in-depth understanding on the nature, frequency, process and the hot spots of ragging with reference to UOX, signifying the worth to investigate the underlying reasons behind its prevalence in order to formulate remedial actions. Accordingly, the current investigation was conducted as a follow up study to expose UOX specific parameters behind the prevalence and continuation of ragging.

\subsection{METHODOLOGY}

Considering the sensitiveness of the subject matter, achieving the validity and the credibility of responses from students was a challenge. It was noticed that generally the students are reluctant to respond to online questionnaires genuinely due to the fear of getting traced. Though using paper and pencil seems a better alternative, executing such a survey in the Faculties while preventing student manipulations was seen as a difficult task. For instance, students can be organized under the influence of certain leadership (staff/students/union) in order to manipulate the responses to end up with favorable results. Accordingly, in-depth interviews were identified as the most appropriate data collection method in fulfilling the research objectives. On the other hand, identifying and incorporating the students who are willing to voluntarily provide genuine information on ragging was considered as the method for sample selection.

Consequently, a sample of undergraduates of both genders $(n=20,60 \%$ male and $40 \%$ female, age: 20-25) of UOX representing all the faculties, student's clubs/societies, religions, sportsmen/sportswomen and academic levels were selected on a voluntary basis to conduct this qualitative study. The subjects were ensured at the onset of the interview that their identity will be kept confidential. Considering the necessity that the respondents should feel comfortable and sense privacy in reporting sensitive matters, the interviews were conducted in person by the investigator 
face-to-face with the interviewee in an isolated room within the university premises during an average time of 45 minutes per interview. While maintain a continuous rapport with the interviewee the investigator noted down all the information provided.

\section{Findings - A model for ragging at UOX}

Aligned with literature, the subjects revealed below mentioned social, cultural, political and sex related facets as reasons for the prevalence of ragging at UOX.

\subsection{BRAINWASHING; MISLEADING /FALSE INFORMATION GIVEN TO THE NEWCOMERS} ("THELA GASEEMA")

False /misleading information provided to the freshers by the ragging perpetrators (seniors) regarding the overall academic environment at UOX seems to have an enormous impact on the sustenance of ragging. This brainwashing process is reported to occur systematically way before getting enrolled in to the university via 'kuppi' sessions taking place in their hometowns (in temples, tuition classes) every weekend. These ' $k u p p i$ ' classes become the first source of information for most of the freshers to come to UOX. These sessions start soon after receiving their A/L results and initially take the form of providing genuine assistance in teaching the difficult subject modules (or modules which are difficult to comprehend as English being the mode of instruction at UOX) related to first year to attract the juniors. These sessions gradually convert in to brainwashing sessions identified as 'thela gaseeme'.

As clarified by the subjects, seniors not revealing the correct picture to the juniors from the beginning regarding the academic setup, role of academic staff, administration, seniors, student union ...etc is a strategy for the sustenance and continuity of ragging. Academic staff/admin staff/ non-academic staff are being introduced as of 'NO USE'; not doing their job properly /maintaining a huge gap with students/ lectures are not comprehendible ...etc. Accordingly, the freshers lose faith on academic and administrative staff unduly based on the misleading theories preached, and thereby severely impacting a healthy teacher-student's relationship. The seniors have been introduced as the 'saviors' of freshers and it is repeatedly preached that the juniors cannot survive university life without the support of seniors. The main points highlighted and exaggerated as benefits offered by the seniors as consequences of ragging are the assistance in academics; conducting 'kuppi' classes for difficult/less comprehendible subject modules mainly due to language problem, providing lecture notes, past papers, finding boarding places, finding industrial training places significantly for the marginalized students with financial, language and other difficulties. Consequently, strongly believing in these statements, the freshers get ragged tolerating all the physical, verbal and emotional harassments due to the fear of losing the connection of seniors and the said privileges offered by them. Further they have the fear of getting cornered in the batch, which extends throughout until graduation ('ala weema').

It is true that the pro-ragging seniors help the juniors to find boarding houses on district basis. However, the hidden agenda would be the convenience in executing ragging activities on a district basis safely with no disturbance in those locations. Meanwhile the seniors do nourish a group of prorag followers from among the freshers.

The freshers themselves with time and experience at UOX realise that most the above statements have no validity. For instance, the subjects particularly stated that, once they proceed with university life there are seniors who genuinely help with academic activities on humanitarian basis. But they are definitely not the pro-ragging seniors who preached during rag season. Similarly, the past papers and reference material can be easily accessed through the library by any student.

Most of the ragging activities are carried out by the pro-ragging senior students under the guise of the key concepts like introduction, orientation, getting to know, skill development, social harmony, personality development, leadership training ...etc with reference to freshers and the related events 
are conducted with proper approvals from university academics and administration. Some of the events/gatherings organised for freshers with ragging as the underlying agenda are as below.

Conducting Events- 'Pirith', Trips, Sports days, Talent shows, New year festival 'Avurudu Uthsawaya', Social, bucket

Political campaigns - 'keta selaweema', pickets, events of student unions

Progress meetings - Early morning, overnight at gathering places

Ragging sessions; 'watha kireema' - at the canteens, hostels, boarding places, safe houses outside university premises

\section{2) MANIPULATING INFERIORITY / SUPERIORITY COMPLEX BASED DIVISIONS TO STRENGTHEN RAGGING ; THE SOCIAL DIMENTION}

Inferiority complexes-based divisions of some of the students justify ragging and enhance long-term sustenance from level to level, feeding the notion that "We are there for the underprivileged" established by senior ragging perpetrators. Some of such divisions of privileged vs underprivileged are based on district of the school attended, difficulty in communicating in English language, difficulty in understanding Sinhala (by Tamil students), low z-score or being selected to follow degree programmes which are low in hierarchy within a faculty due to less GPA, difficulty in understanding certain technical modules due to following subjects in the arts stream during A/Ls, suffering with long term physical / psychological sicknesses, disabilities, issues in the physical appearance, family related issues, childhood related issues and relationship issues. Seniors justify that they do not allow freshers to speak in English language and enforce them to wear a prescribed dress code and to eat pre-defined food only from specific canteens to implant the sense of equity, equivalence in-between such divisions. It was revealed that most of these perpetrators share the common characteristics of coming from under privileged sociocultural, economic and family backgrounds, who had less opportunity and recognition in their schools/ society or having political agendas. Inferiority related ragging reduces confidence level of students, making them highly dependent on seniors while breaking down strongly built personalities with irreversible psychological impacts.

\subsection{INFLUENCING FACTORS}

The pressure coming from pro-ragging seniors, peers, political parties, student unions, ragging prone lecturers \& administrators and industry is found to influence the continuity of ragging. This can be recognised as a systematised interconnected follow-up network. In such a context, while some seniors contribute to ragging with purpose and intention others are compelled to do so to survive the unbearable pressure coming from the said parties. It was reported that the initial ideas on ragging are implanted in freshers from some of the reputed tuition class teachers and then continues nearly a period of one year in hometowns since receiving A/L results and until getting enrolled for university. This gradually makes their minds conditioned to accept ragging as a norm. The majority of the freshers are scared and submit as commanded by the seniors without complaint thinking that this torture will last only during the rag season. However, it was reported that there are certain degree programmes at UOX that have ragging continuing up to the final year and monitored by the industry ensuring its sustenance.

\subsection{CONTRIBUTION OF SOME OF THE STAFF MEMBERS}

Unethical/unhealthy practices and behaviour of a minority of staff members have been identified to provide supportive testimony for the theories discoursed by raggers against the staff. Huge gap maintained between staff and students, difficulties in approaching to discuss academic and personal matters, difficulties in understanding / following lectures, unethical and unprofessional conduct (harassments, intimidation, aggressive behaviour) of some of the staff members and the conduct of ragging prone staff members are some of the highlighted issue by the subjects. Apart from above factors, lecturers being unfairly strict on $80 \%$ attendance, favouritism, taking personal revenges by 
penalizing the students in their exams/ submissions....etc, some of the decisions made by inquiry committees /Board of Residence and Discipline which are unfair, being unfair/ unethical in assessments, statements made by some lecturers which indicate the power dynamics and signs of revenge from students (e.g. "Don't forget that your degree is in our hands.") were reported as other matters related to staff. Accordingly, the freshers have a fair confusion as to whom they can trust. The conduct of this minority of members has become a valid reason behind students not believing / trusting the staff while supporting and strengthening some of the theories behind ragging and its sustenance.

\subsection{THE ROLE PLAYED BY STUDENT UNIONS}

The dual and safe role played by the student union in balancing in-between the staff vs student affairs while fulfilling their political agendas is another reason for the continuation of ragging. While they try to convince the admin/staff that they stand against ragging, they have played a decisive role in generating fear and perpetrating ragging in the junior batches. Ragging can be identified as the innermost agenda of most of the events conducted/organized by the Union for the freshers in their respective faculties; New Year celebrations, pirith ceremony, fresher's nights, talents show, cricket matches, drama festivals etc. clearly demonstrate this scenario.

\subsection{THE ROLE PLAYED BY ADMINISTRATION}

As per the student's viewpoint, follow-up actions on the reasonable requests of students are not taken promptly by the administration. According to them such matters are discussed in meetings repetitively with no significant progress for months leading to frustrations. The delays made in following the university protocols and procedures related to purchasing of equipment/accessories, obtaining services, building construction...etc is a major factor which increases the frustration of students regarding the administration even if some of such delays are beyond the control of the administration. The attitude problem of most of staff members/administrative officers was raised as another issue behind this scenario. Above frustrations of students provide opportunity for the raggers to further establish their justifications against the administration to attract followers from junior batches.

Students on the other hand highlighted that certain important evidences handed over to the administration related to ragging incidents/harassments have not been investigated properly and action taken. Consequently, the seniors have established the notion that there is no point in complaining regarding ragging/harassments to the administration as no action will be taken. Accordingly, the students who attempt in eradicating ragging/harassments are demotivated/ demoralized while the raggers/harassers are motivated and empowered under the impression that the top administration is with them.

\subsection{RAGGING AS A MEANS OF FULFILLING SEXUAL DESIRES}

Treating differently due to gender, gazing, stalking, name calling and joking in sexual ways and making violent statements using sex associated filthy language were identified as part of ragging highlighting its purpose as a means of fulfilling sex related desires of male students. In some of the degree programmes each fresher is called by a name (card) given by the seniors after testing their eligibility during progress meetings. These names given to the male students are much of sexual nature (obscene/filthy words related to sex organs, obscene sexual acts, sex related defects...etc) having a background story/song depicting obscene sexual acts. While byhearting the names of all the batchmates the freshers are forced to perform the said degrading sexual acts (allied to the card) in front of others.

\section{Concluding remarks on remedial actions}

The UOX community who have been blinded by the misleading, faulty myths of raggers could be directed towards a hope of light by reflecting on the revelations of this study. In the process of eradicating ragging from the UOX, it would be essential for all the members of the administrative and 
academic staff to be unanimously maintaining one voice consistently against ragging. On the other hand, the staff should use a friendly, sensitive, supportive, trustworthy and ethical approach in dealing with the students ensuring their availability for students in academic, personal, financial as well as any other issue. While coming up with innovative programs to transfer correct information to the newcomers beforehand, strategic actions should also be taken to empower their self-esteem, personality, soft skills and leadership skills. Actions should be taken to identify students with psychological imbalances and thereby prone to ragging mentality and to assist them with counselling and therapy as necessary. It is essential to remove the long-established respect/authority seeking structural dependency on seniors whose underlying agenda is ragging/harassment. In doing so, innovative strategies/programmes should be adopted to nourish the notion that the respect and seniority have to be earned through a humanistic and sincere approach by setting good examples; helping with academic activities and language issues, finding boarding places, finding training places...etc without any hidden agendas but purely on brotherhood, sisterhood and humanity.

A holistic, strategic, innovative and proactive approach is needed to gradually break the wellestablished deep-rooted bonds in the interconnected network of raggers between the diverse layers; schools, tuition classes, academic levels, alumni, student union and the political parties, carefully considering the roles of each and every layer.

\section{References}

Athukorala, D.R.(2018). Background and remedies for ragging and violence in Universities, 22nd Annual General Meeting, Alumni Association, University of Colombo.

Bandara, S.M.R. (2002). Nawaka Wdaya Saha Navaka Sathuta, Sri Lanka National Library Archives, ISBN 955-96233-2-X. Daily mirror. (2018-08-22).Tough action against ragging imperative, Retrieved from http://www.dailymirror.lk/article/Tough-action-against-ragging-imperative-154358.html

Daily Mirror .(2016-03-30). Denying ragging does not take it away, Retrived from

http://www.dailymirror.lk/opinion/Denying-ragging-does-not-take-it-away/172-107587

Gamage,s.(2020). Ragging is responsible for the misogynistic and anti-intellectual culture in our universities. Daily FT.

Retrieved from http://www.ft.lk/columns/Ragging-is-responsible-for-the-misogynistic-and-anti-intellectual-culture-in-ouruniversities/4-701438

Gamage,s.( 2017). Psychological, sociological, and political dimensions of ragging in sri lankan universities, Social Affairs: A Journal for the Social Sciences. Vol.1 No.7, pp. 13-21.

Jayawardhana, T and Gamage,B.M (2017, December 29). Torture at universities How the Mentally Disturbed Carryout Ragging. Dailymirror Online.

Retrived from http://www.dailymirror.lk/opinion/Torture-at-universities-How-The-Mentally-Disturbed-Carryout-

Ragging/172-143009

Jayasinghe, S. (2017, January 27). Ragging continues to torment undergraduates. Dailymirror Online. Retrieved from http://www.dailymirror.lk/122815/Ragging-continues-to-torment-undergraduates.

Jayarathne, S. (2019, August 11). Are rag leaders psychopaths. Silumina, pp. 14.

Rajasingham,s. (2017-04-25). Ending Ragging in Sri Lanka's Universities, Retrieved from

http://www.dailymirror.lk/print/opinion/Ending-Ragging-in-Sri-Lanka-s-Universities/172-127730

Wajahat, A.( 2013). Harassment due to ragging Procedia - Social and Behavioral Sciences Volume 113, 7 February 2014, Pages 129-133. 